\title{
Resident recruitment in the COVID-19 era: factors influencing program ranking by residents applying to a family medicine-emergency medicine training program
}

\author{
Jennifer Leppard ${ }^{1}$. Avik Nath ${ }^{1}$. Warren J. Cheung ${ }^{1,2}$
}

Received: 23 February 2021 / Accepted: 28 June 2021 / Published online: 26 August 2021

( ) The Author(s), under exclusive licence to Canadian Association of Emergency Physicians (CAEP)/ Association Canadienne de Médecine d'Urgence (ACMU) 2021

\begin{abstract}
Objective The COVID-19 pandemic has created numerous unique challenges for the recruitment of prospective trainees. Cancellation of visiting electives and in-person interviews created challenges for programs to showcase elements that have been shown to influence applicants' program selection, including geographical considerations and program collegiality. Novel strategies have been recommended and employed to facilitate candidate recruitment, but it is unclear how influential such strategies are on candidates' program ranking. It is also unclear what factors influence program selection among CCFP(EM) candidates. We sought to evaluate the impact of novel recruitment strategies on applicants' ranking of the University of Ottawa CCFP(EM) program and determine factors which were most influential in applicants' first-choice program selection. Methods An online survey was distributed to all candidates $(n=127)$ who applied to the University of Ottawa CCFP(EM) program. The survey instrument included 33 items. Respondents were asked to rate on a 3-point scale how influential specific recruitment strategies were on their ranking of our program and the influence of different training factors on their selection of first-choice program.

Results The survey response rate was 27\% (34/127). Recruitment strategies rated as most positively influential included virtual one-on-one meetings with program directors (100\%), virtual Q\&A sessions (77.8\%), virtual communication with chief residents $(73.3 \%)$, and a mailed personalized recruitment package (72.2\%). The top factors influencing applicants' first-choice program selection included: collegiality between faculty and residents (96.4\%); level of responsibility given to residents (96.4\%); support within the program (96.4\%); and procedural opportunities within the program (96.3\%).

Conclusion Facilitating virtual personal interaction with program leadership is highly influential in how CCFP(EM) candidates rank programs. CCFP(EM) candidates value characteristics of a training program over the geographical location and available amenities. Program leaders should consider these findings when recruiting prospective candidates.
\end{abstract}

Keywords Resident recruitment $\cdot$ CaRMS $\cdot$ CCFP(EM) $\cdot$ Emergency medicine

\section{Résumé}

Objectif La pandémie de COVID-19 a créé de nombreux défis uniques pour le recrutement de stagiaires potentiels. L'annulation des stages optionnels et des entrevues en personne a créé des difficultés pour les programmes de présenter des éléments qui se sont avérés influer sur la sélection des programmes des candidats, y compris les considérations géographiques et la collégialité du programme. De nouvelles stratégies ont été recommandées et utilisées pour faciliter le recrutement des candidats, mais on ne sait pas dans quelle mesure ces stratégies influent sur le classement des programmes des candidats. On

Jennifer Leppard

jleppard@toh.ca

1 Department of Emergency Medicine, University of Ottawa, The Ottawa Hospital, Civic Campus, 1053 Carling Ave, Ottawa, ON K1Y 4E9, Canada

2 Clinical Epidemiology Program, Ottawa Hospital Research Institute, Ottawa, ON, Canada 
ne sait pas non plus quels facteurs influencent la sélection des programmes parmi les candidats au CCFP(EM). Nous avons cherché à évaluer l'impact de nouvelles stratégies de recrutement sur le classement des candidats du programme CCFP(EM) de l'Université d'Ottawa et à déterminer les facteurs qui ont eu le plus d'influence sur la sélection du programme de premier choix des candidats.

Méthodes Un sondage en ligne a été distribué à tous les candidats $(n=127)$ qui ont postulé au programme CCFP(EM) de l'Université d'Ottawa. L'instrument d'enquête comprenait 43 points. Les répondants devaient évaluer sur une échelle de 3 points l'influence de stratégies de recrutement spécifiques sur leur classement de notre programme et l'influence de différents facteurs de formation sur leur choix du programme de premier choix.

Résultats Le taux de réponse au sondage était de 27\% (34/127). Les stratégies de recrutement jugées les plus influentes sont les réunions virtuelles en tête-à-tête avec les directeurs de programme (100\%), les séances virtuelles de questions-réponses (77,8\%), la communication virtuelle avec les chefs résidents (73,3\%) et l'envoi par courrier d'un dossier de recrutement personnalisé $(72,2 \%)$. Les principaux facteurs influençant le choix du programme de premier choix des candidats comprenaient: la collégialité entre le corps professoral et les résidents (96,4\%); le niveau de responsabilité donné aux résidents (96,4\%); le soutien au sein du programme $(96,4 \%)$; et les possibilités de procédures au sein du programme $(96,3 \%)$.

Conclusion Faciliter l'interaction virtuelle personnelle avec le leadership du programme a une grande influence sur la façon dont les candidats du CCFP(EM) classent les programmes. Les candidats CCFP(EM) valorisent les caractéristiques d'un programme de formation plutôt que à l'emplacement géographique et les commodités disponibles. Les chefs de programme devraient tenir compte de ces constatations lorsqu'ils recrutent des candidats éventuels.

\section{Clinician's capsule}

What is known about the topic?

Pandemic restrictions have required changes to resident recruitment strategies. Geography and program camaraderie are important to medical student program selection.

\section{What did this study ask?}

Which recruitment strategies impact resident candidates' program selection? What factors influence program ranking amongst CCFP(EM) candidates?

\section{What did this study find?}

Personal interaction with program leadership highly influences candidates' program ranking. Candidates value the characteristics of training programs over geographical amenities.

\section{Why does this study matter to clinicians?}

Residency programs should consider these unique factors when choosing recruitment strategies for prospective candidates.

\section{Introduction}

The COVID-19 pandemic has created a number of unique challenges for medical education including recruitment of prospective trainees [1]. In the spring of 2020, many Post-Graduate Medical Education (PGME) offices cancelled visiting clinical electives across Canada during peak elective season for potential applicants to the Family
Medicine-Emergency Medicine enhanced skills program (CCFP(EM)). Subsequently, in-person interview days were adapted to prevent the spread of the virus [2]. These in-person activities have traditionally provided critical information influencing rank order decisions by programs, and program selection by applicants. Candidates get to know the city and its various amenities from their experiences while on elective or during interview day. Furthermore, these in-person experiences enable trainees to directly observe residentfaculty dynamics and the training experiences of learners at different clinical sites.

Recent Canadian data published by the Canadian Resident Matching Service (CaRMS) has shown that factors such as geography, available leisure opportunities, and collegiality between residents and faculty highly influence how medical students rank their first-choice residency program [3]. Geographical considerations and resident/faculty camaraderie have also been described as key determinants in other studies looking at emergency medicine applicants $[4,5]$. However, it is unclear if these factors are similarly influential on residents applying to a 12-month CCFP(EM) program.

Cancellation of elective experiences and in-person interviews presented new challenges for programs with respect to rethinking recruitment strategies. Various suggestions have been described in the literature to mitigate these challenges such as leveraging social media, video tours, and recruitment boxes $[6,7]$. Some of these strategies were employed by the CCFP(EM) Program at the University of Ottawa (UOttawa) for the 2020-21 academic year to recruit applicants [8]. To date, however, there is a paucity of literature examining the effectiveness of such recruitment strategies on program selection. 
This study aimed to: (1) determine what factors are most influential on applicants' preferred ranking choice of a CCFP(EM) program; and (2) evaluate the impact of novel recruitment strategies on applicants' ranking of the UOttawa CCFP(EM) program. Results will help optimize future resident recruitment methods.

\section{Methods}

\section{Study and survey design}

This was a cross-sectional survey of Canadian Family Medicine (FM) residents applying to a $\mathrm{CCFP}(\mathrm{EM})$ training program in the $2020 \mathrm{CaRMS}$ cycle. This study received ethics exemption from the Ottawa Health Science Network Research Ethics Board.

\section{Participants and recruitment}

All 127 candidates who applied to the UOttawa CCFP(EM) Program received an email invitation to participate. The invitation was sent on December 9, 2020, after the rank list submission deadline to CaRMS, and the survey was closed on December 16, 2020 prior to the release of match results. A reminder email was sent five days after the initial invitation. A cover letter was included emphasizing that participation would have no impact on candidate selection. No compensation was offered to participants.

\section{Survey design and content}

We designed an anonymous 33-item survey in SurveyMonkey (Supplementary material-Appendix 1) based on the experience and expertise of the study team members and review of previously published data from CaRMS [3]. The first series of questions asked respondents about elective and residency experience at our institution and whether they were invited to interview. The second section asked respondents to rate the degree of influence of the local recruitment strategies on their ranking of our program using a 3-point scale: not influential (NInf), somewhat influential (SInf), very influential (VInf). The final portion of the survey examined the influence of factors on candidates' first choice program selection. These factors were adapted from previously published data from CaRMS [3], and each was rated using the same 3-point scale as above.

\section{Analysis}

Simple descriptive statistics including frequencies and percentages were used to report survey results. Data analysis was conducted using Microsoft Excel for Mac version 16.45.
Responses marked "not applicable" were removed from the analyses. Recruitment strategies and factors influencing firstchoice program selection were analyzed by collapsing the SInf and VInf anchors because they represented a positive influence.

\section{Results}

The survey was completed by 34 applicants, representing a response rate of $27 \%$. Of all respondents, $17.7 \%$ were UOttawa residents, $26.5 \%$ indicated that they had completed an on-site elective, and $50 \%$ had been invited for an interview.

Figure 1a displays the proportion of responses for each recruitment strategy. $61.3 \%$ of candidates indicated that they had participated in one or more recruitment strategies. The strategies that were most frequently rated by respondents as positively (SInf + VInf) influential were virtual one-onone meetings with the program directors $(100 \%)$, virtual townhalls $(77.8 \%)$, virtual communication with chief residents $(73.3 \%)$, and a mailed recruitment package $(72.2 \%)$. The least influential strategy was found to be the program's social media accounts $(52.6 \%$ of respondents indicated it was "not influential").

Nine respondents had the opportunity to complete an elective at our training site with $100 \%$ indicating it was positively influential in their program ranking.

Figure $1 \mathrm{~b}$ displays the proportion of responses of the influence of factors on the selection of participants' firstchoice program. The factors that were most frequently rated by respondents as positively (SInf + VInf) influential included collegiality between faculty and residents $(96.4 \%)$, level of responsibility given to residents (96.4\%), support within the program $(96.4 \%)$, and procedural opportunities within the program $(96.3 \%)$.

\section{Discussion}

Several recent studies have offered suggestions to enhance recruitment strategies for programs during the current pandemic $[6,7]$. Much focus has been placed on social media strategies but in our study, our social media strategies (i.e. Instagram, Twitter, blog posts) were rated as not influencing program ranking by the majority of respondents. A survey of osteopathic medical students found that while $27 \%$ gleaned information about prospective programs online, only $10 \%$ reported that it influenced their decision-making around program selection [9]. With the rapidly evolving popularity of social media, more specific research should be conducted to clarify the influence of social media on program selection.

In this study, strategies involving bidirectional communication between candidates and program leadership were 
Fig. 1 a Influence of novel recruitment strategies on UOttawa CCFP(EM) program ranking. b Influence of factors in selection of first-choice program location a Influence of novel recruitment strategies on UOttawa CCFP(EM) program ranking

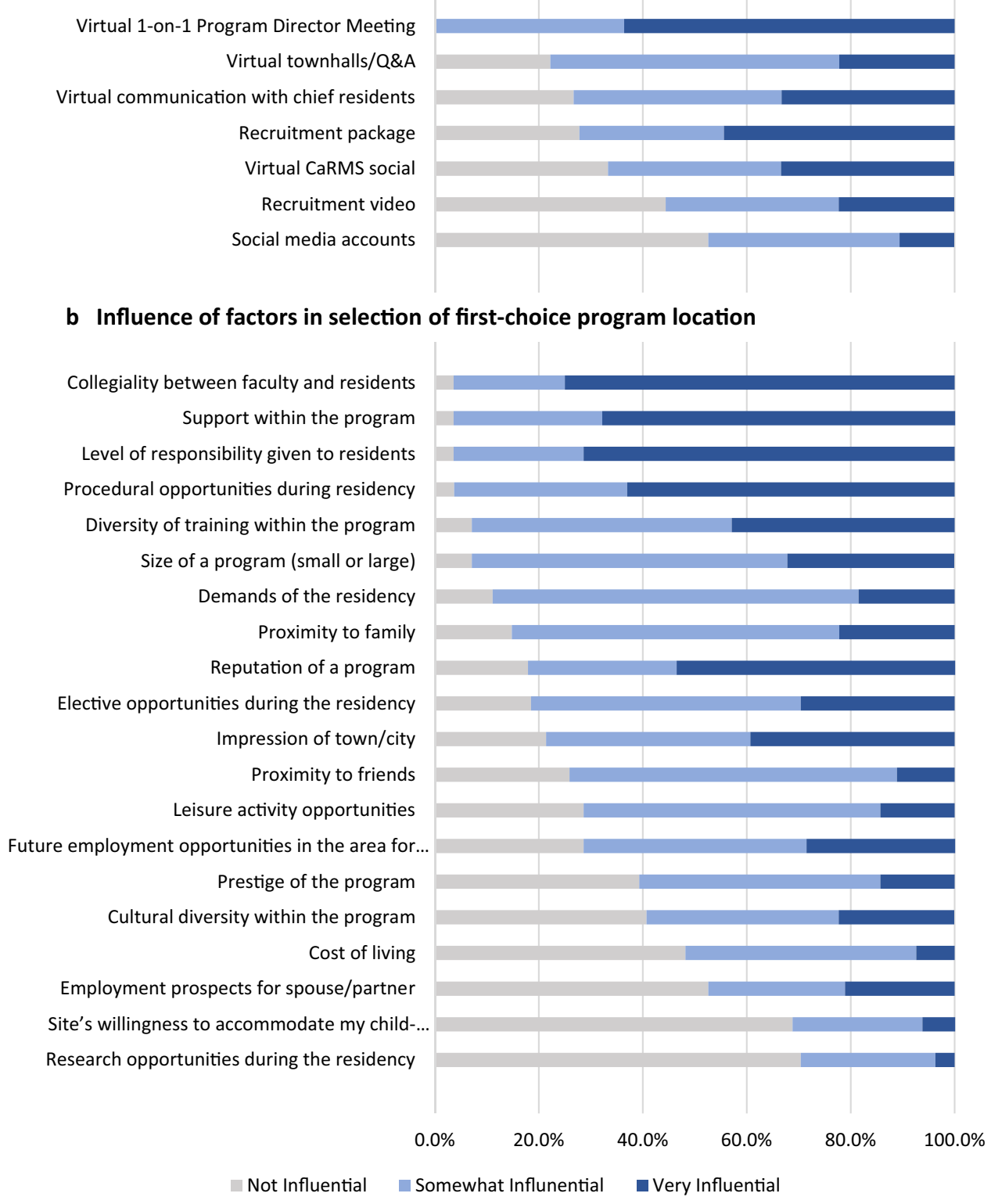

found to be most influential on how trainees selected their first-choice program. With current technologies, numerous options can be employed to facilitate virtual communication [6]. We encourage programs to consider promoting events that enable applicants to interact virtually with current residents, faculty, and program leadership.

Personalized recruitment packages were found to positively impact program selection. These packages contained a handwritten note from program leadership, a "featured alumni" pamphlet, and a promotional badge reel. Although there are costs associated with such packages, they provide another avenue to add a personal touch to recruitment. Our finding that personalized recruitment packages positively impacted program selection aligns with similar strategies that have been recommended in the literature to facilitate candidate recruitment [7].

Respondents who participated in an elective at our centre indicated that it was positively influential in how they ranked our program. We postulate that electives enable prospective candidates to observe 'program personality' and collegiality between faculty and residents, elements previously shown in the literature to be highly valued by EM applicants [4, 5]. We suggest that permitting visiting electives should be a high priority once pandemic travel restrictions are lifted. Furthermore, while there are financial and time benefits to applicants having virtual interviews [10], these findings suggest that enabling candidates to visit program sites may assist them in program ranking. 
In selecting first-choice program sites, our results indicate that perception of collegiality between trainees and faculty was very influential, which is consistent with the literature [3-5]. In one study, applicants to an EM program indicated that friendliness (95\%) and program environment (87\%) were most influential in program selection [5]. Our respondents also reported that the in-training experiences such as opportunities for procedures, level of responsibility given, and support within the program were much more influential in their first-choice program selection than has been previously demonstrated in Canadian data [3]. Additionally, geographical factors did not seem to be as influential for respondents in this survey when compared to prior studies where program location was consistently rated amongst the most influential factors in program selection [3-5]. It should be noted, however, that these prior studies examined preferences of medical students applying to a multi-year residency program whereas our survey specifically explored factors influencing residents applying to a one-year enhanced skills program. It is possible that CCFP(EM) applicants place greater value on the training experience, as opposed to geographic amenities, due to the intense and condensed nature of training.

The sample size of this single-centre study limits the generalizability and transferability of results. Furthermore, respondents were part of a single cohort of prospective candidates applying to one EM training program amidst a global pandemic. It is unclear to what degree the pandemic impacted factors influencing their program ranking. Future studies could examine for any differences in factors perceived to impact program ranking between applicants to different CCFP(EM) programs and also during non-pandemic times.

\section{Conclusion}

Facilitating virtual personal interaction with program leadership is highly influential in how CCFP(EM) candidates rank programs. Factors influencing $\mathrm{CCFP}(\mathrm{EM})$ candidate program ranking may differ from medical students with higher value placed on the characteristics of a training program over the geographical location and available amenities. Program leadership should consider these factors when designing recruitment strategies for prospective candidates.
Supplementary Information The online version contains supplementary material available at https://doi.org/10.1007/s43678-021-00177-w.

Author contributions J.L. and A.N. conceived the idea. J.L. collected and analyzed the data. J.L. drafted the manuscript. J.L., A.N., and W.J.C. reviewed the manuscript and contributed substantially to its revision. J.L. takes responsibility for the study as a whole.

Funding None.

\section{Declarations}

Conflicts of interest None.

\section{References}

1. Mann U, Nayak JG. The potential impact of COVID-19 on the Canadian resident matching service: unique future challenges faced by urology residency programs and applicants. Can Urol Assoc J. 2020;14(5):E167-8.

2. Canada TAoFoMo. Virtual interviews for the 2021 medicine subspecialty match, pediatric subspecialty match and family medicine, enhanced skills match 2020. Available from: https://afmc. $\mathrm{ca} / \mathrm{en} / \mathrm{media}-\mathrm{releases} / \mathrm{may}-26-2020$.

3. Canadian Resident Matching S. Most influential factors on R-1 match discipline and program location choice 2020. Available from: https://www.carms.ca/data-reports/r1-data-reports/influ ential-factors.

4. Yarris LM, Deiorio NM, Lowe RA. Factors applicants value when selecting an emergency medicine residency. Western J Emerg Med. 2009;10(3):159-62.

5. DeSantis M, Marco CA. Emergency medicine residency selection: factors influencing candidate decisions. Acad Emerg Med. 2005;12(6):559-61.

6. Haas MRC, He S, Sternberg K, Jordan J, Deiorio NM, Chan TM, et al. Reimagining residency selection: part 1-a practical guide to recruitment in the post-COVID-19 era. J Grad Med Educ. 2020;12(5):539-44.

7. Bernstein SA, Gu A, Chretien KC, Gold JA. Graduate medical education virtual interviews and recruitment in the era of COVID19. J Grad Med Educ. 2020;12(5):557-60.

8. Rosenberg H, Nath A, Leppard J, Syed S. New challenges and mitigation strategies for resident selection during the coronavirus disease pandemic. CJEM. 2020;22:E14.

9. Schweitzer J, Hannan A, Coren J. The role of social networking websites in influencing residency decisions. J Am Osteopath Assoc. 2012;112(10):673-9.

10. Davis MG, Haas MRC, Gottlieb M, House JB, Huang RD, Hopson LR. Zooming in versus flying out: virtual residency interviews in the era of COVID-19. AEM Educ Train. 2020;4(4):443-6. 